\title{
ORIGINAL ARTICLE \\ The effect of brief versus individually tailored dietary advice on change in diet, lipids and blood pressure in patients with inflammatory joint disease
}

\author{
Maria Grorud Fagerhøi'*, MS, RD, Silvia Rollefstad², MD, PhD, Sissel Urke Olsen', \\ MS, RD and Anne Grete Semb², MD, PhD \\ 'Department of Clinical Service, Diakonhjemmet Hospital, Oslo, Norway; ${ }^{2}$ Preventive Cardio-Rheuma Clinic, \\ Department of Rheumatology, Diakonhjemmet Hospital, Oslo, Norway
}

Abstract

Background: Patients with inflammatory joint diseases (IJD) have an increased risk of cardiovascular disease (CVD) compared to the general population. Nutritional advice has been shown to influence CVD risk factors. Our objective was to evaluate whether an individually tailored dietary counselling versus a brief standardised advice on heart-friendly diet had comparable effect on change in diet, lipids and blood pressure (BP) in patients with IJD.

Methods: Thirty-one patients with IJD aged 40-80 years received a brief standardised advice (4 min) on heartfriendly diet by a physician. Sixteen of the patients were randomised to receive an additional, individually tailored, heart-friendly dietary counselling session $(60 \mathrm{~min})$ by a dietitian. Change in dietary habits, measured by a validated questionnaire (SmartDiet), lipids, BP and C-reactive protein (CRP) were assessed after 8 weeks of follow-up.

Results: After 8 weeks, the average increase in SmartDiet score was 5.1 and 5.7 points in the diet group (DG) and the control group $(\mathrm{CG})$, respectively $(p=0.65)$. Low-density lipoprotein cholesterol (LDL-c) was reduced by $12.6 \%$ in the DG versus $2.4 \%$ in the CG $(p=0.05)$. There were no significant differences between the two groups regarding change in $\mathrm{BP}$, lipids or CRP.

Conclusion: Individually tailored dietary counselling resulted in more heart-friendly food choices in patients with IJD. However, the change in SmartDiet score was comparable for IJD patients receiving a brief nutritional advice and individually tailored heart-friendly dietary counselling. Further studies evaluating the longitudinal effects of dietary advice on CVD outcome in patients with IJD are warranted.

Keywords: nutrition; dietary advice; diet; cardiovascular disease; inflammatory joint disease; lipids; blood pressure

Received: 12 September 20 17; Revised: I5 April 20 I8;Accepted: I2 July 20। 8; Published: 4 September 20 I8

$\mathrm{C}$ ardiovascular disease (CVD) is the major cause of mortality worldwide, accountable for approximately 17.5 million deaths per year, representing $31 \%$ of all global mortality (1). Despite the fact that CVD mortality has decreased since the 1970s, it still remains as the leading cause of death in Norway (2). It is well established that patients with inflammatory joint diseases (IJD), such as rheumatoid arthritis (RA), psoriatic arthritis (PsA) and ankylosing spondylitis (AS), have an increased risk of atherosclerotic CVD compared to the general population $(3,4,5,6,7)$. Several CVD risk factors are present in patients with IJD, including chronic inflammation, which may contribute to the increased CVD risk in this group. In addition, patients with RA have 2-3 times more asymptomatic atherosclerotic plaques in the carotid arteries compared to the general population (8). Thus, RA patients have an increased risk of myocardial infarction and sudden death $(6,9,10)$. Hyperlipidaemia is prevalent in RA patients and has been reported to be present in $55-60 \%$ of the patients (11). In a meta-analysis comparing RA patients with and without hypercholesterolaemia, a $73 \%$ increased risk of CVD morbidity was reported in RA patients with increased lipid levels (12).

The role of food in the management of RA is controversial, and despite this, RA patients have been reported to regard food to be of importance in relation to their symptom severity and have been willing to change diet in an attempt to decrease their symptoms (13). Different hypotheses regarding the importance of diet in IJD patients have been proposed, which indicates that diet and lifestyle 
may play a role in both the development of and the course of the rheumatic disease $(14,15)$. Laboratory animal studies suggest that diet may have an impact on disease activity in IJD patients, although human studies are still scarce (16). Various dietary patterns, interventions and nutrients have been tested over the past decades $(16,17)$. The potential effect of this is still questionable. Today, effective anti-rheumatic treatment (synthetic disease-modifying anti-rheumatic drugs [sDMARDs]/biologic disease-modifying anti-rheumatic drugs [bDMARDs]) exists (16), which may reduce the importance of diet as a potential contributor to aggravation of disease activity. Nevertheless, diet will still be of considerable importance related to other aspects of IJD. Ensuring adequate and proper nutrition may be essential for further prognosis and in the prevention of comorbidities. The increased risk of CVD in IJD patients makes the prevention of comorbidities of especially importance. Modification of lifestyle-related risk factors, such as diet, is important in CVD prevention $(18,19,20,21,22)$. Nutritional advice has been reported to influence CVD risk factors $(18,23)$.

SmartDiet, a validated questionnaire developed by the Lipid Clinic at Oslo University Hospital, has been shown to efficiently provide good estimates of diet and lifestyle habits in clinical practice (24). SmartDiet includes both qualitative and quantitative questions about average use of different food groups and beverages.

Whether the impact of traditional CVD risk factors on CVD morbidity in IJD patients diverges from that of the general population remains unknown $(4,12,25)$. Furthermore, there is a knowledge gap regarding the effect of nutritional advice on change in dietary habits and CVD risk factors in IJD patients. The objective of this article was to evaluate whether an individually tailored heart-friendly dietary counselling by a dietitian and a standardised brief advice on heart-friendly diet given by a physician had comparable effects on change in diet, lipids and blood pressure (BP).

\section{Methods and materials}

\section{Patients}

Patients with IJD from the rheumatology outpatient clinic at Diakonhjemmet Hospital, or from primary care physicians, were referred to the Preventive Cardio-Rheuma Clinic, Department of Rheumatology, Diakonhjemmet Hospital, between January and June 2016. Inclusion criteria were as follows: patients must have RA, PsA or AS; be under the age group of 40-80 years; should be statin-naïve and have an indication for statin therapy as a primary or secondary prevention of CVD. Exclusion criteria were the following: 1) already diagnosed atherosclerotic CVD as previous myocardial infarction, coronary intervention (coronary artery bypass grafting or percutaneous coronary intervention), transient ischaemic attack/ischaemic stroke, stenosis of the carotid artery $>50 \%$ and/or symptomatic carotid artery atherosclerosis; 2) $\mathrm{BP}>160 / 100 \mathrm{mmHg}$ and/or medically treated hypertension; or 3 ) indications of familial hypercholesterolaemia (total cholesterol [TC] $>7.5 \mathrm{mmol} / \mathrm{L}$ and lowdensity lipoprotein cholesterol [LDL-c] $>4.9 \mathrm{mmol} / \mathrm{L}$ ).

This study was an open randomised controlled clinical trial (RCT) with two treatment groups: a diet group (DG) and a control group (CG) (Fig. 1). A statistician developed the computer-generated randomisation list. Two independent secretaries compiled randomisation envelopes, which was based on the randomisation list. Inside the envelope a sheet describing the allocated treatment group was inserted into a dyed sheet, to further ascertain that it was not possible to reveal the treatment group without opening the envelope. Patients in the study were assigned randomisation numbers sequentially. Randomisation number and treatment group were recorded in each Case Report File.

All patients at the Cardio-Rheuma Clinic answered a questionnaire encompassing smoking status, presence of diabetes mellitus, medication history, family history of premature CVD in first-degree relatives, presence of established CVD, history of stroke, transient ischaemic attack and peripheral vascular disease. All the participants followed a standard procedure for CVD risk evaluation, which has previously been described in detail (26). Blood samples were drawn for laboratory tests including lipid profile, C-reactive protein (CRP), erythrocyte sedimentation rate, renal and liver function tests. Blood pressure was measured. The SmartDiet questionnaire was administered to all the patients by a dietitian. The data collection fulfilled the conditions of privacy and information security according to the Declaration of Helsinki (27). The study was approved by the South East Health Authority Ethical Committee for Medical Research (No. 2015/2087), and all the patients gave written informed consent to participate in the study.

\section{Dietary counselling}

\section{Brief standardised advice}

The standardised dietary advice was given by an experienced cardiologist (Anne Grete Semb) who has used this set-up for several years at the Preventive Cardio-Rheuma Clinic. A list of five standardised clauses related to heartfriendly food was given along with a brochure including heart-friendly food items, which was developed by dietitians at Diakonhjemmet Hospital. Furthermore, due to time restriction during the consultation, the patients were informed that a detailed discussion about the patients' diet could not be possible. This brief advice has been fixed to take $4 \mathrm{~min}$. The standardised advice and the brochure 


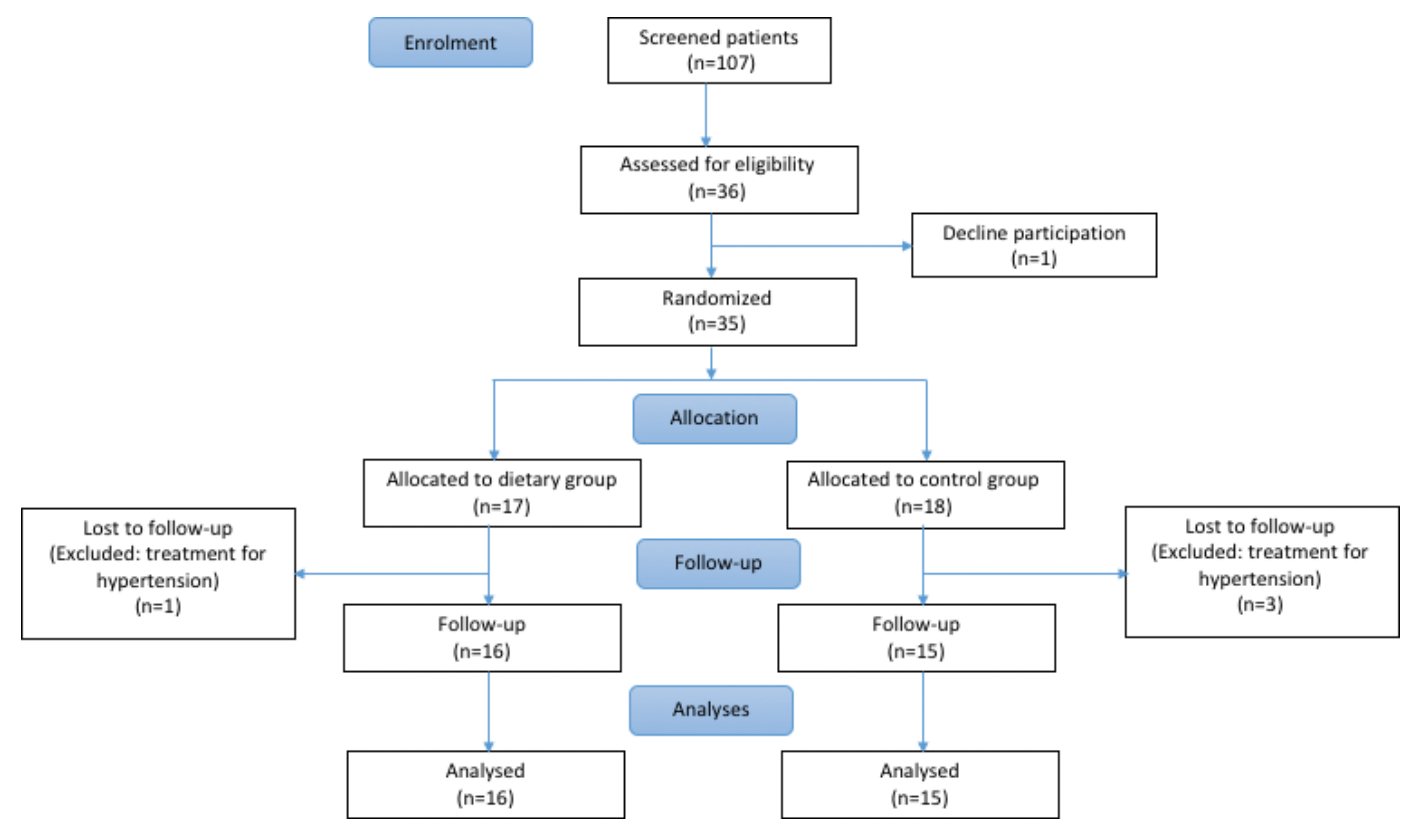

Fig. 1. Flowchart of study design.

have therefore been the same for patients in both study groups. The study also validated the use of the brochure together with the standardised brief advice as information towards change in food habits.

Individual tailored diet counselling

Participants in the DG received an individually tailored heart-friendly dietary advice during a session of $60 \mathrm{~min}$, which was given by a dietitian. The information provided was based on the answers from the SmartDiet questionnaire. Main topics were discussed with all the participants, emphasising the importance of replacing saturated fat from full-fat dairy products, animal products, snacks, pastries and chocolate with unsaturated fat from marine sources, such as oily fish, and vegetable sources including oils, nuts, almonds, seeds and avocado (6, 28, 29, 30, 31, 32, 33).

Furthermore, to increase the intake of fiber through wholegrain cereals, especially oat $(34,35)$, fruits, berries and vegetables including legumes $(36,37)$, information on how to read food labels was also addressed. The importance of salt reduction $(38,39)$ was emphasised to all the participants, and alcohol consumption was discussed thoroughly if the patient had a high alcohol consumption and/or hypertriglyceridaemia. Coffee habits were addressed if frequently use of unfavourable brewing methods were reported (40). Portion control was not addressed specifically; however, patients with a high body mass index (BMI) asked for personal guidance regarding weight loss.

The participants were encouraged not to take other supplements than cod liver oil or similar omega-3 supplements if they were already taking such when entering the trial, and they were not asked to stop taking them. However, participants taking supplements other than cod liver oil or omega-3 supplements were not excluded from the trial.

\section{SmartDiet}

The third version of the SmartDiet questionnaire (24) was handed out and collected by the dietitian in both groups at baseline and after 8 weeks of follow-up. SmartDiet has been developed in Norway and was designed to fit the Norwegian food habits. The questionnaire is not designed to measure the quantity of food, rather the frequency of food consumption and habits; therefore, portion size was not known. On the other hand, the questionnaire offers an opportunity to discuss central points of the patient's dietary habits, and compliance was assessed by using the answers at 8 weeks follow-up. The questionnaire contains 15 point scoring questions, and it is possible to obtain a score between 15 and 45 points. An increase in score of at least 3 points from baseline to 8 weeks indicated a clinically significant improvement of the diet (24). A low score $(\leq 27)$ indicates that improvement in many areas is needed to obtain a more heart-friendly diet. A medium score (28-35 points) indicates that the diet still needs improvement, while a high score ( $\geq 36$ points) implies that the participants have healthy dietary habits. In the following, some sample questions from the SmartDiet questionnaire are presented. Each question has three or four response categories. Luncheon meat: what kind of luncheon meat do you use most often in your sandwich? A list of high- and low-fat luncheon is provided in addition to a category of consuming luncheon meats less than once 
a week, or never. Another sample question was about fish for dinner: how many times do you eat a fish product, and how many of those include fatty fish?

\section{CVD risk factors}

The physician performed measurement of waist circumference, BP and a 12-lead electrocardiogram (ECG). Smoking status, physical activity habits, comorbidities, medication use and family history of CVD were also recorded. Body weight was measured by the dietitian at both baseline and at 8 weeks.

The blood samples were drawn in relation to the consultation with the physician, and the laboratory tests included $\mathrm{TC}$, high-density lipoprotein cholesterol (HDL-c), triglycerides (TG) and CRP, which were measured at the hospital laboratory by routine procedures using COBAS 6000 modular and COBAS 8000 modular delivered by Roche Diagnostics Norge AS. LDL-c was calculated according to Friedewald's formula (41).

Brachial BP was measured three times if it was found to be $>140 / 90 \mathrm{mmHg}$, using an Omron ${ }^{\circledR} 7$ series and Welch Allyn ${ }^{\circledR}$ ProBP 3400 Series, by the physician, after 5 min rest in a supine position. A mean of the two last measurements was calculated. At 8 weeks follow-up, the dietitian performed the waist circumference and $\mathrm{BP}$ measurements.

\section{Statistics}

Demographic characteristics of patients with IJD are presented as crude data, and the results are expressed as mean \pm standard deviation (SD), or median and interquartile range (IQR) for normally and non-normally distributed continuous variables, respectively. Categorical variables are presented as numbers and percentages (\%). Variables with a normal distribution were analysed using independent samples t-test and analysis of co-variance (ANCOVA), for group comparisons, with baseline values as covariates. A supplementary model including baseline values, BMI, systolic BP (SBP) and diastolic BP (DBP) as covariates was conducted. Non-normally distributed variables (TG and CRP) were log-transformed before comparison. For skewed continuous variables (HDL-c), the non-parametric Mann-Whitney U test was conducted to compare per cent change from baseline to follow-up. The primary analyses followed the intention-to-treat principle. Missing data were handled using pairwise deletion. The sample size calculations were performed by a statistician. With an estimated difference between the groups of three SmartDiet points, and an SD of 2.69 for change from baseline to follow-up, at least 13 patients were calculated to be needed in each group to show a statistical difference (two-sided t-test, $5 \%$ significance level) between the groups at $80 \%$ strength. The corresponding count for $90 \%$ strength was 17 patients completed in each group.
The level of statistical significance was set at a $p \leq 0.05$ for all analyses. Statistical Package for the Social Sciences (SPSS) version 23 was used for the statistical analyses.

\section{Results}

\section{Patient characteristics}

Baseline characteristics of the study participants are shown in Table 1. Thirty-one patients with IJD (RA, $n=16$; PsA, $n=7$; and AS, $n=8$ ) were included in the study, of whom 16 were randomised to the DG. Females dominated in both groups (DG: 56.3\%, CG: 60.0\%) $(p=0.83)$. The participants in the DG had lower BMI $(p=0.03)$ and waist circumference $(p=0.002)$ compared to those in the CG. The lipid profile was comparable, and median CRP was $<5 \mathrm{mg} / \mathrm{L}$ in both groups. SBP $(p=0.04)$ and DBP ( $p=0.04)$ were higher among patients in the CG compared to those in the DG. There were no significant differences in medication use between the groups. Among the patients in the DG, $81.3 \%$ were using bDMARDs compared to $53.3 \%$ of the patients in the CG $(p=0.14)$, while 43.8 and $60.0 \%$ of the patients in both groups used sDMARDs $(p=0.37)$, respectively. Current prednisolone medication use was present in 6.3 and $20.0 \%$ among the DG and CG patients, respectively ( $p=0.33$ ).

Diet

There were no significant differences in change in SmartDiet score from baseline to after 8 weeks follow-up between the DG and the CG $(p=0.65)$, and no further change was observed after adjusting for baseline SmartDiet score, BMI and BP $(p=0.26)$ (Table 2$)$.

At baseline, $43.8 \%$ and $73.3 \%$ of the patients in the CG and the DG had a low SmartDiet score $(p=0.95)$; on the other hand, more patients in the DG group had a medium SmartDiet score compared to the CG: $56.3 \%$ versus $20.0 \%(p=0.04)$, respectively (Fig. 2$)$. After 8 weeks of follow-up, the SmartDiet score in the DG and CG was for: 1) low SmartDiet score: 6.3\% versus 26.7\% $(p=0.17)$ and 2) medium SmartDiet score: $81.3 \%$ versus $53.3 \%(p=0.14)$ (Fig. 2). At least 3 points improvement in SmartDiet score was obtained by $87.5 \%$ in the DG $(p<0.001)$ and $80.0 \%$ in the CG $(p<0.001)$.

The increase in SmartDiet score from baseline to 8 weeks follow-up reflects several changes in dietary habits (supplementary Table 1). In summary, the changes towards a more heart-friendly diet were greatest among patients in the DG, who more frequently used vegetable oil/liquid margarine for cooking $(93.8 \%$ vs. $60.0 \%)$ $(p=0.04)$ and had a higher consumption of whole grain bread $>6$ grams of fibre $/ 100 \mathrm{~g}(93.8 \%$ vs. $60.0 \%)(p=0.04)$. On the other hand, patients in the CG reported frequently use of butter/hard margarine on bread compared to the DG $(46.7 \%$ vs. $6.7 \%)(p=0.02)$. 
Table 1. Baseline characteristics of all patients, diet group and control group

\begin{tabular}{|c|c|c|c|c|}
\hline Baseline characteristics & All patients, $n=3 \mathrm{I}$ & Diet group, $n=16$ & Control group, $n=15$ & $p$-value ${ }^{a}$ \\
\hline Diagnosis RA/PsA/AS n (\%) & $16(51.6) / 7(22.6) / 8(25.8)$ & $7(43.8) / 4(25.0) / 5(31.3)$ & $9(60.0) / 3(20.0) / 3(20.0)$ & $0.72^{c}$ \\
\hline Sex male/female $\mathrm{n}(\%)$ & |3(4|.9)/I8 (58.I) & $7(43.8) / 9(56.3)$ & $6(40.0) / 9(60.0)$ & $0.83^{b}$ \\
\hline Age mean $\pm S D$ & $54.94 \pm 9.96$ & $53.38 \pm 10.36$ & $56.60 \pm 8.91$ & 0.36 \\
\hline \multicolumn{5}{|l|}{ Lipids } \\
\hline $\mathrm{TC}(\mathrm{mmol} / \mathrm{L})$ mean $\pm \mathrm{SD}$ & $5.88 \pm 0.84$ & $6.10 \pm 0.85$ & $5.64 \pm 0.78$ & 0.13 \\
\hline HDL-c (mmol/L) mean \pm SD & $1.48 \pm 0.42$ & $1.46 \pm 0.47$ & $1.50 \pm 0.38$ & 0.82 \\
\hline LDL-c (mmol/L) mean \pm SD & $3.7 \mathrm{I} \pm 0.83$ & $3.90 \pm 0.95$ & $3.52 \pm 0.66$ & 0.21 \\
\hline TG (mmol/L) median (IQR) & $1.29(1.08)$ & $1.29(0.98)$ & $1.29(1.23)$ & 0.91 \\
\hline \multicolumn{5}{|l|}{ Blood pressure, mean \pm SD } \\
\hline Systolic (mmHg) & $129.06 \pm|7.1|$ & $122.96 \pm 14.30$ & $135.57 \pm 17.89$ & 0.04 \\
\hline Diastolic (mmHg) & $80.85 \pm 9.80$ & $77.34 \pm 10.16$ & $84.60 \pm 8.14$ & 0.04 \\
\hline \multicolumn{5}{|c|}{ Inflammation biomarkers, median (IQR) } \\
\hline CRP $(\mathrm{mg} / \mathrm{L})$ & $2.00(4.00)$ & $2.00(4.00)$ & $3.50(5.25)$ & 0.15 \\
\hline Sedimentation rate $(\mathrm{mm})$ & $17.00(16)$ & $16.50(16)$ & $17(14)$ & 0.72 \\
\hline \multicolumn{5}{|l|}{ Antropomethry, mean \pm SD } \\
\hline Weight (kg) & $81.04 \pm 12.26$ & $76.43 \pm 15.89$ & $85.95 \pm 13.35$ & 0.08 \\
\hline BMI (kg/m2) & $27.56 \pm 4.89$ & $25.76 \pm 1.19$ & $29.49 \pm 1.13$ & 0.03 \\
\hline Waist circumference $(\mathrm{cm})$ & $96.48 \pm 11.44$ & $90.69 \pm 9.94$ & $102.67 \pm 9.78$ & 0.002 \\
\hline \multicolumn{5}{|l|}{ Smoking habits, n (\%) } \\
\hline Daily smoking & $7(22.6)$ & $3(18.8)$ & $4(26.7)$ & $0.69^{c}$ \\
\hline Social smoking & $2(6.5)$ & $2(12.5)$ & $0(0.0)$ & $0.48^{c}$ \\
\hline \multicolumn{5}{|l|}{ Comorbidities, n (\%) } \\
\hline Combined dyslipidaemia $^{d}$ & $3(9.7)$ & I (6.3) & $2(14.3)$ & $0.59^{c}$ \\
\hline Hyperlipidaemia $^{e}$ & $14(45.2)$ & $9(56.3)$ & $5(33.3)$ & $0.20^{\mathrm{b}}$ \\
\hline Hypertension ${ }^{f}$ & $8(25.8 \mathrm{I})$ & $2(12.6)$ & $6(40.0)$ & $0.15^{\mathrm{b}}$ \\
\hline Diabetes & $0(0.0)$ & $0(0.0)$ & $0(0.0)$ & - \\
\hline Carotid plaque & $26(83.9)$ & I3 (8I.3) & I3 (86.7) & $1.0^{c}$ \\
\hline \multicolumn{5}{|l|}{ Medication, n (\%) } \\
\hline Prednisolone & $4(12.9)$ & I (6.3) & $3(20.0)$ & $0.33^{c}$ \\
\hline NSAIDs & $12(38.7)$ & $6(37.5)$ & $6(40.0)$ & $0.89^{\mathrm{b}}$ \\
\hline sDMARDs & $16(51.6)$ & $7(43.8)$ & $9(60.0)$ & $0.37^{b}$ \\
\hline bDMARDs & $21(67.7)$ & $13(81.3)$ & $8(53.3)$ & $0.14^{c}$ \\
\hline
\end{tabular}

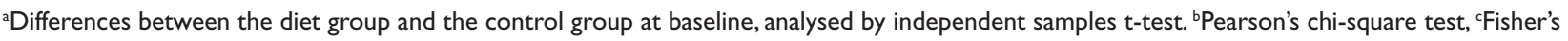
exact test ${ }^{\mathrm{d}}$ Triglycerides $>2 \mathrm{mmol} / \mathrm{L}, \mathrm{HDL}<\mathrm{I} \mathrm{mmol} / \mathrm{L}{ }^{\mathrm{e}}$ Total-cholesterol $>6 \mathrm{mmol} / \mathrm{L}$ 'Systolic blood pressure $>140 \mathrm{mmol} / \mathrm{LRA}$, rheumatoid arthritis; PsA, psoriatic arthritis; AS, ankylosing spondylitis; SD, standard deviation; TC, total cholesterol; HDL-c, high-density lipoprotein cholesterol; LDL-c, low-density lipoprotein cholesterol;TG, triglycerides; IQR, interquartile range; BMI, body mass index; CRP, C-reactive protein; NSAIDS, non-steroidal anti-inflammatory drugs; sDMARDs, synthetic disease-modifying anti-rheumatic drugs; bDMARDs, biologic disease-modifying anti-rheumatic drugs. Bold values: significant values

\section{Lipids}

TC $(p=0.13)$, LDL-c $(p=0.21)$, HDL-c $(p=0.82)$ and TG $(p=0.91)$ were comparable in both DG and CG at baseline [Table 1]. Eight weeks after the individually tailored heart-friendly dietary counselling by a dietitian, no significant differences were found between the groups regarding TC $(p=0.29)$, LDL-c $(p=0.11)$, HDL-c $(p=0.50)$ or TG $(p=0.63)$ (Table 2$)$. Adjustment for baseline values of BMI and BP did not change the outcome, nor did the adjustment of omega-3 usage influence TG levels in any of the groups. Figure 3 illustrates the per cent change in lipids from baseline to follow-up. Both groups had an average decrease in TC from the first to the final consultation, corresponding to $-6.3 \%$ versus $-0.4 \%$ in the DG and the CG $(p=0.19)$, respectively. A mean per cent decrease of -12.6 and $-2.4 \%$ in LDL-c $(p=0.05)$ and a mean per cent increase of 3.3 and $2.2 \%(p=0.55)$ in HDL-c in the DG and CG, respectively, were demonstrated. There was a comparable mean per cent increase in TG in both the groups (DG 7.1\% vs. CG 8.0\%) ( $p=0.95)$.

\section{Blood pressure}

No significant mean differences in SBP or DBP between the DG and the CG after 8 weeks follow-up were revealed 


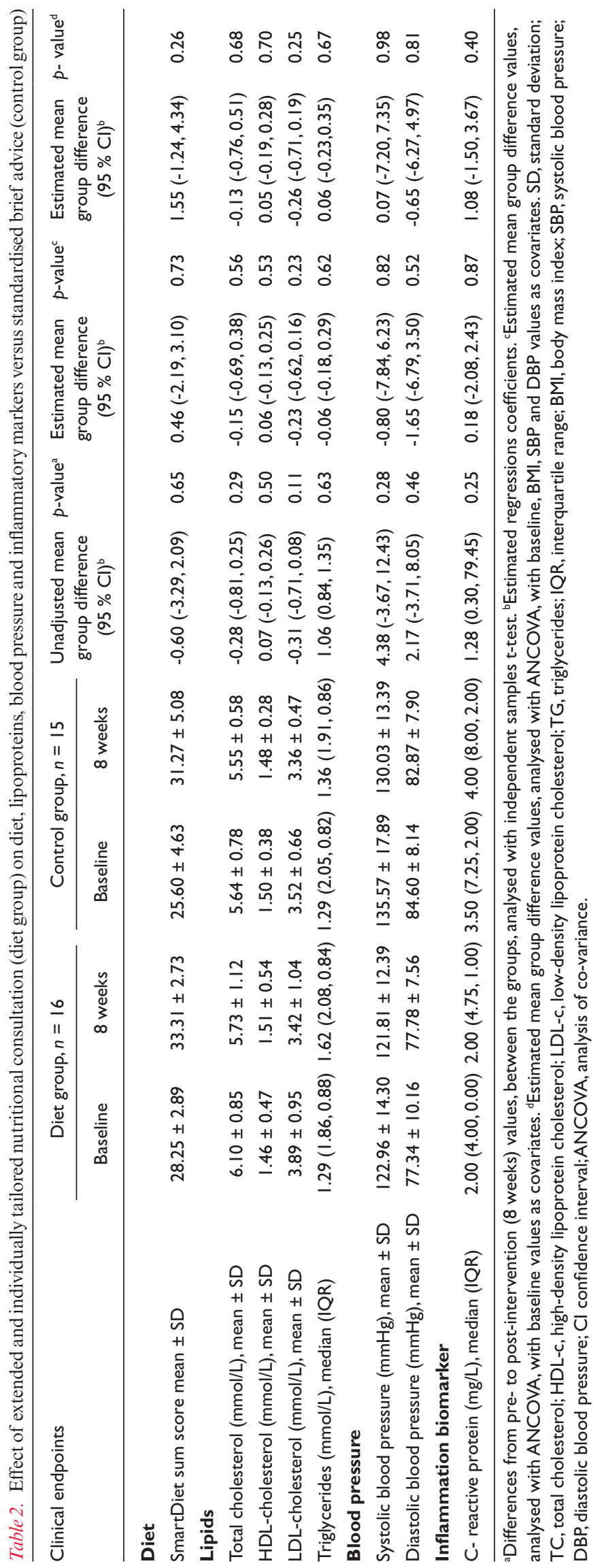




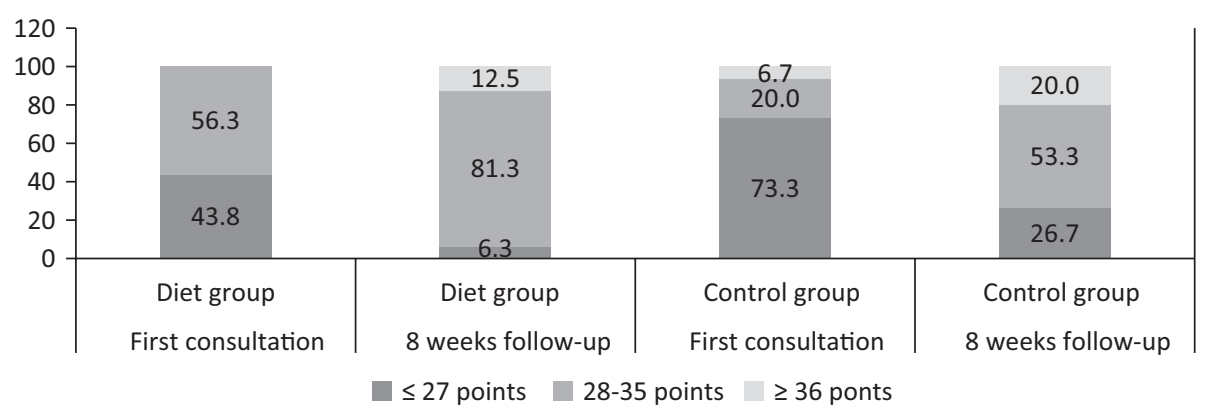

Fig. 2. Distribution of score obtained by SmartDiet.

Points equal to or less than 27 indicates that the diet should be improved in several areas, a score of 28-35 points indicates that the diet could still be improved to become more heart-friendly, while a score of $\geq 36$ points indicates that the dietary habits are heart-friendly and healthy.

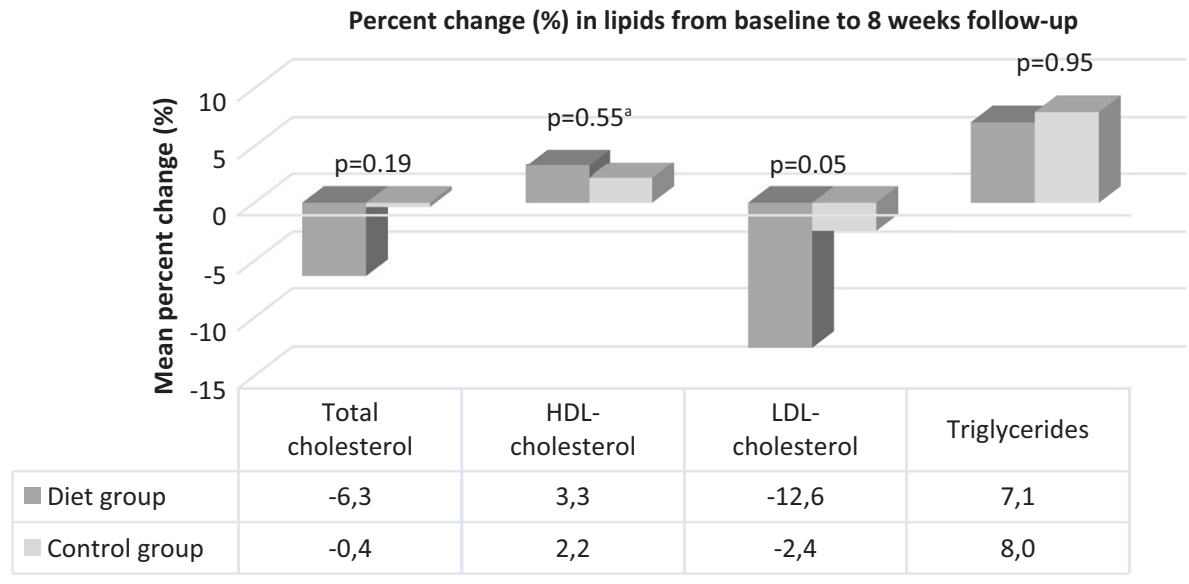

Fig. 3. Per cent change in lipids from baseline to 8 weeks of follow-up in the diet group and control group. Differences between the diet group and the control group are analysed by an independent samples t-test.

aMann-Whitney U test.

( $p=0.28, p=0.46)$ (Table 2). Adjusting for baseline values of BMI and BP did not change the outcome (Table 2). Both groups showed a decline in SBP from baseline to 8 weeks follow-up $(-1.15 \mathrm{mmHg}$ vs. $-5.53 \mathrm{mmHg}$ in the DG and CG, respectively, corresponding to a per cent change in SBP of 0.45 and $1.47 \%(p=0.32)$ (Fig. 4). DBP was, on average, increased by $0.44 \mathrm{mmHg}(1.31 \%)$ in the DG and decreased by $-1.73 \mathrm{mmHg}(3.49 \%)$ in the $\mathrm{CG}(p=0.44)$.

\section{Inflammatory markers}

No differences were observed in change in CRP values from baseline to follow-up between the DG and the CG $(p=0.25)$ (Table 2). Adjusting for baseline values of BMI and BP did not change the outcome. Median CRP was unaltered $(2.0 \mathrm{mg} / \mathrm{L})$ from the first to the final consultation in the DG, while a modest increase from median $3.5 \mathrm{mg} / \mathrm{L}$ to $4.0 \mathrm{mg} / \mathrm{L}$ was revealed in the $\mathrm{CG}$ after 8 weeks $(p=0.75)$.

\section{Discussion}

We have shown that a standardised brief advice combined with a nutritional purchase guide brochure may be sufficient to improve the dietary habits towards a heartfriendly diet in patients with IJD. This study successfully improved dietary habits defined by $>3$ points change in the SmartDiet score. Importantly, even short sessions on heart-friendly diet advice enable patients to make changes with clinical effect. However, the nutritional advice provided by a dietitian resulted in significant better compliance to the heart-friendly diet after 8 weeks.

\section{Dietary counselling}

Few studies have compared the effectiveness of an individually tailored heart-friendly dietary counselling by a dietitian versus brief advice provided by physicians (23). One study reported a $12 \%$ short-term reduction in LDL-c after counselling by a dietitian versus a 7\% reduction after a physician consultation (23). However, the observed effect 


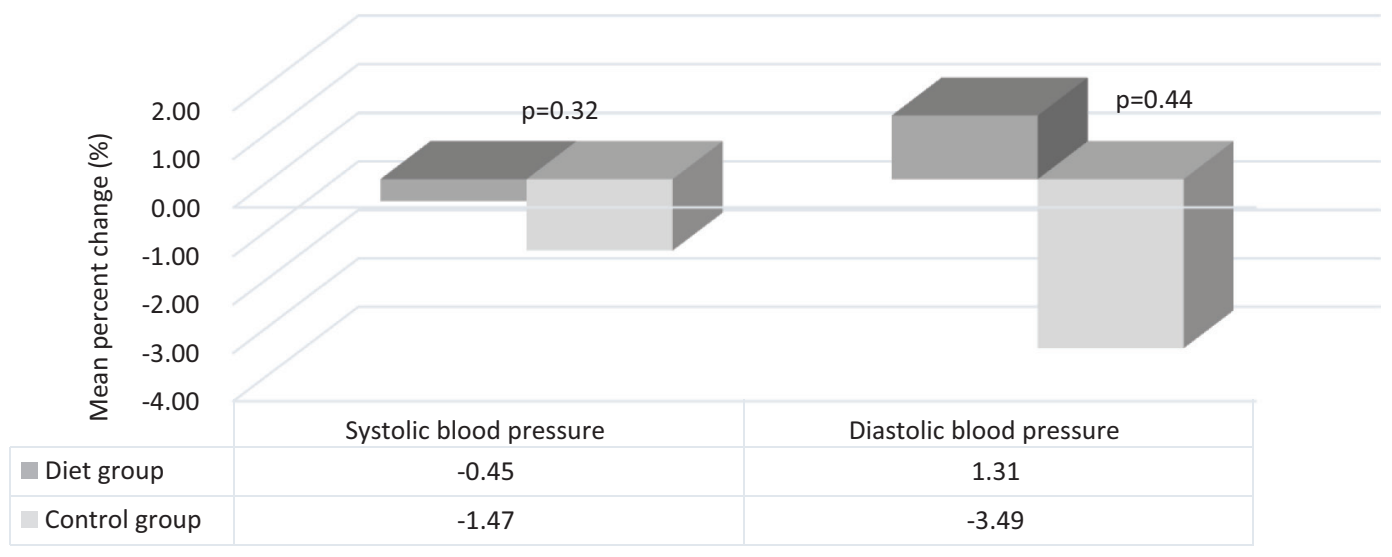

Fig. 4. Per cent change in blood pressure from baseline to 8 weeks of follow-up in the diet group and control group. Differences between the diet group and the control group are analysed by an independent samples t-test.

did not sustain after 1 year, indicating that the effects of diet change on LDL-c after advice by a dietitian or a physician are comparable at 1 year follow-up. Another recently published study investigated the effectiveness of a brief dietary intervention on CVD risk factors in patients with hyperlipidaemia (42). In that study, the patients received a tailored dietary counselling mainly based on the Mediterranean diet and the Portfolio diet (43), combined with a nutritional educational manual, regarding eating patterns. After 6 weeks, a significant reduction in energy-dense/nutrient-poor foods was demonstrated. These results support the effect of a brief and single dietary counselling.

Professor Ingar Hjermann was a pioneer in dietary research and prevention of CVD, and through The Oslo Diet and Antismoking study it was revealed that men receiving dietary advice, primarily on reducing saturated fatty acids (SFA) and increasing their intake of polyunsaturated fatty acids (PUFA), had an average of $13 \%$ greater decrease in TC compared to the CG (44). A 20-year follow-up of this study showed that men in the intervention group still had a more conscious approach to diet and lifestyle and ate less SFA and cholesterol and more PUFA than the CG (45). Consequently, the Oslo study demonstrated that making lifestyle interventions, such as diet counselling, provides evident and lifelong effects, suggesting that diet counselling may result in permanent change in dietary habits.

Although several lifestyle intervention programmes have shown to be effective, it requires great resources and may not be available in the majority of health care systems. There is a knowledge gap regarding the effectiveness of less intensive counselling in relation to the minimum of, and the duration of, sessions needed to obtain alteration in dietary habits and clinical effects on other CVD risk factors (46). However, we have through our study contributed to this knowledge gap regarding patients with IJD.
Lipids

There were no differences in the mean change in TC, LDL-c or HDL-c after 8 weeks between the two groups in our study. However, the per cent reduction was numerically greater for TC and significantly higher for LDL-c in the DG, which favours individual tailored diet counselling.

Our findings are in accordance to previous studies (23, $43,47)$, where heart-friendly dietary habits have demonstrated a reduction in LDL-c from 5 to $30 \%(43,47)$. The differences observed in mean per cent change in LDL-c levels between the two groups in our study may be attributed to a more unfavourable choice of fat sources in the CG. Interestingly, a reduction of $1 \mathrm{mmol} / \mathrm{L}$ in LDL-c has been shown in large international, placebo controlled, randomised statin trials to be related to a risk reduction of future CVD of $21 \%$ (48). Promising results from post hoc analyses in two large statin trials found that both the lipid and risk reduction of future CVD in patients with IJD and non-IJD were comparable (49). Future prospective studies are warranted to answer whether LDL-c reduction due to dietary intervention has a clinical effect on CVD outcomes.

Results from a prospective cohort study revealed that replacing $5 \%$ of the energy intake from SFA with an equivalent energy intake from PUFAs or whole grain was associated with a 25 and $9 \%$ decrease in CVD risk, respectively (50).

Several lifestyle factors may influence TG levels, such as weight reduction, high consumption of refined carbohydrates (51), especially fructose (52) and/or high alcohol consumption (53). However, we did not observe any significant weight reduction in our study; rather, there were only minor changes of refined carbohydrates and beverages, including alcohol consumption, which cannot probably explain an increase in TG in either of the groups. Despite the increase in TG levels in our study, 
the mean levels were still $<1.7 \mathrm{mmol} / \mathrm{L}$ in both groups, which is the recommended level for TG (51).

\section{Blood pressure}

We observed no significant differences in SBP or DBP after 8 weeks of follow-up between the DG and the CG. However, a clinical important reduction in SBP was observed in the CG $(\sim 5 \mathrm{mmHg})$, but not in the DG, and studies have shown that even a small reduction in SBP/ DBP $(\sim 2 \mathrm{mmHg} / 1 \mathrm{mmHg})$ may cause a reduction in CVD morbidity and mortality (54).

A high consumption of sodium is a well-known risk factor for hypertension (55). Patients in the DG were recommended to decrease their salt intake. Unfortunately, SmartDiet does not give the opportunity to evaluate salt intake. However, in a recent review it was concluded that sodium modification in normotensive patients did not significantly alter BP (56). In our study, $87.4 \%$ of the patients in the DG were normotensive versus $60.0 \%$ in the CG. An increase in the consumption of fruit and vegetables is another dietary factor that has been associated with a reduction in $\mathrm{BP}(57,58,59)$, while excessive alcohol consumption is related to an increased risk of hypertension (60). There were no differences in fruit and vegetable intake or alcohol consumption between the groups after 8 weeks.

\section{Inflammatory markers}

No significant changes in CRP levels were observed between the two groups after 8 weeks of follow-up. The majority of patients in this study were treated with potent anti-inflammatory medication, which may explain the absence of alterations in CRP levels. Previous studies have shown that dietary intervention may affect inflammation, but weight loss seems to be of more importance (61).

\section{Limitations}

A limitation of our study is the collection of dietary information using a questionnaire. Recall bias will potentially lead to less accuracy on a patient's dietary habits (62), while guidance by a dietitian during answering the questionnaire may have increased the risk of pleasing bias (62). Another limitation of the study is the difference in baseline data between the two groups. A priori calculations were performed to obtain $80 \%$ strength, for which a minimum of 13 patients was necessary in each group. Despite meeting the estimated minimum number of patients, there were significant differences between the groups at baseline, both in BMI and BP. The a priori power calculations were based on the difference between the groups, and not within each group. The changes in SmartDiet score within each group were comparable. There was a difference in baseline SmartDiet score, as well as differences in dietary quality between the groups at baseline.
The change in diet quality was greatest among patients in the DG. However, both groups had major changes in their food habits during the study period.

SmartDiet score was used to evaluate changes in dietary habits of the participants, where an increase of at least 3 points was set as a basis to denote an improvement in diet (24). However, the 3-point score in the SmartDiet has never been assessed (24). Nevertheless, the questionnaire has been validated against a 7-day 'weighed food consumption record' (24) and was shown to provide good estimates of dietary fat and fiber intake, while the estimated intake of fish, vegetables and snacks was evaluated to be somewhat more imprecise. The lower sensitivity for evaluation of changes in the latter mentioned foods is a limitation of the SmartDiet method. The questionnaire has been used in several studies $(63,64)$, and also as a model in the development of a Canadian version of the questionnaire (65).

A further limitation of the study is the small sample size and the short-term follow-up. Studies have shown that to achieve long-lasting dietary alterations, it will require counselling on several occasions with an intensified dietary and lifestyle guidance $(46,66)$, and there is a need for studies testing a more intensive intervention with multiple sessions to be able to illuminate the longterm effect of change in dietary habits. However, this is the first study to evaluate the effect of dietary advice in patients with IJD.

\section{Conclusion}

Our findings indicate that both standardised brief dietary advice and individually tailored dietary counselling lead to short-term improvement in heart-friendly diet evaluated by SmartDiet score in patients with IJD. Regarding health care resources, the positive result of a brief standardised advice may be of interest, although an individually tailored dietary counselling by a dietitian seems superior to brief advice regarding change to more heartfriendly food choices and reduction of LDL-c. Studies on long-term effects of dietary advice on CVD outcome in patients with IJD are warranted.

\section{Acknowledgements}

We are grateful to all the patients for participating, to Anne Stormyr Eirheim (RN and sonographer) for her valuable contribution regarding performance of the ultrasound of carotid arteries and to Cecilie Okkenhaug for the laboratory procedures.

\section{Conflict of interest and funding}

The authors declare no conflict of interest. This work was supported by the funding from the University of Oslo and Diakonhjemmet Hospital. 


\section{References}

1. Tzoulaki I, Elliott P, Kontis V, Ezzati, M. Worldwide Exposures to Cardiovascular Risk Factors and Associated Health Effects: Current Knowledge and Data Gaps. Circulation. 2016 Jun 7;133(23):2314-33.

2. Folkehelseinstituttet. Norgeshelsa statistikkbank norgeshelsa. no: Folkehelseinstituttet; [cited 2016 30.06.16]. Available from: http://norgeshelsa.no/norgeshelsa

3. Meune C, Touze E, Trinquart L, Allanore, Y. Trends in cardiovascular mortality in patients with rheumatoid arthritis over 50 years: a systematic review and meta-analysis of cohort studies. Rheumatology (Oxford, England). 2009 Oct;48(10):1309-13.

4. Peters MJ, van der Horst-Bruinsma IE, Dijkmans BA, Nurmohamed, M. T. Cardiovascular risk profile of patients with spondylarthropathies, particularly ankylosing spondylitis and psoriatic arthritis. Seminars in arthritis and rheumatism. 2004 Dec;34(3):585-92.

5. Agca R, Heslinga SC, van Halm VP, Nurmohamed MT. Atherosclerotic cardiovascular disease in patients with chronic inflammatory joint disorders. Heart (British Cardiac Society). 2016 May 15;102(10):790-5.

6. Lindhardsen J, Ahlehoff O, Gislason GH, Madsen OR, Olesen $\mathrm{JB}$, Torp-Pedersen $\mathrm{C}$, et al. The risk of myocardial infarction in rheumatoid arthritis and diabetes mellitus: a Danish nationwide cohort study. Annals of the rheumatic diseases. 2011 Jun;70(6):929-34.

7. Haroon NN, Paterson JM, Li P, Inman RD, Haroon N. Patients With Ankylosing Spondylitis Have Increased Cardiovascular and Cerebrovascular Mortality: A Population-Based Study. Annals of internal medicine. 2015 Sep 15;163(6):409-16.

8. Semb AG, Rollefstad S, van Riel P, van Riel P, Kitas GD, Matteson EL, Gabriel SE. Cardiovascular disease assessment in rheumatoid arthritis: a guide to translating knowledge of cardiovascular risk into clinical practice. Annals of the rheumatic diseases. $2014 \mathrm{Jul} ; 73(7): 1284-8$.

9. Choy E, Ganeshalingam K, Semb AG, Szekanecz Z, Nurmohamed M. Cardiovascular risk in rheumatoid arthritis: recent advances in the understanding of the pivotal role of inflammation, risk predictors and the impact of treatment. Rheumatology (Oxford, England). 2014 Dec;53(12):2143-54.

10. Maradit-Kremers H, Crowson CS, Nicola PJ, Ballman KV, Roger VL, Jacobsen SJ, et al. Increased unrecognized coronary heart disease and sudden deaths in rheumatoid arthritis: a population-based cohort study. Arthritis and rheumatism. 2005 Feb;52(2):402-11.

11. Zegkos T, Kitas G, Dimitroulas T. Cardiovascular risk in rheumatoid arthritis: assessment, management and next steps. Therapeutic advances in musculoskeletal disease. 2016 Jun;8(3):86-101.

12. Baghdadi LR, Woodman RJ, Shanahan EM, Mangoni AA. The Impact of Traditional Cardiovascular Risk Factors on Cardiovascular Outcomes in Patients with Rheumatoid Arthritis: A Systematic Review and Meta-Analysis. PLoS ONE. 2015;10(2):1-18.

13. Martin RH. The role of nutrition and diet in rheumatoid arthritis. The Proceedings of the Nutrition Society. 1998 May;57(2):231-4.

14. Pattison DJ, Symmons DP, Young A. Does diet have a role in the aetiology of rheumatoid arthritis? The Proceedings of the Nutrition Society. 2004 Feb;63(1):137-43.

15. Choi HK. Dietary risk factors for rheumatic diseases. Current opinion in rheumatology. 2005 Mar;17(2):141-6.
16. Tedeschi SK, Costenbader KH. Is There a Role for Diet in the Therapy of Rheumatoid Arthritis? Current rheumatology reports. 2016 May;18(5):23.

17. Smedslund G, Byfuglien MG, Olsen SU, Hagen KB. Effectiveness and safety of dietary interventions for rheumatoid arthritis: a systematic review of randomized controlled trials. Journal of the American Dietetic Association. 2010 May;110(5):727-35.

18. Subhan FB, Chan CB. Review of Dietary Practices of the 21st Century: Facts and Fallacies. Canadian journal of diabetes. 2016 Aug;40(4):348-54.

19. National Center for Chronic Disease P, Health Promotion Office on S, Health. Reports of the Surgeon General. The Health Consequences of Smoking-50 Years of Progress: A Report of the Surgeon General. Atlanta (GA): Centers for Disease Control and Prevention (US); 2014.

20. World Health Organization (WHO). Obesity: preventing and managing the global epidemic: Report of a WHO consultation. Geneva: WHO; 2000. (World Health Organization technical report series; 894).

21. Kostråd for å fremme folkehelsen og forebygge kroniske sykdommer Metodologi og vitenskapelig kunnskapsgrunnlag Nasjonalt råd for ernæring 2011. [Dietary advice to promote public health and Prevent chronic diseases Methodology and fundation of scientific knowledge National Nutrition Council 2011]. Oslo: Helsedirektoratet [The Norwegian Directorate of Health]; 2011. Chapter 19, Kosthold og forebygging av hjerteog karsykdom. [Diet and prevention of cardiovascular disease]; p. 254-262. Norwegian.ogi og vitenskapelig kunnskapsgrunnlag. Oslo: Helsedirektoratet; 2011. p. 254-262.

22. Nordic nutrition recommendations 2012: integrating nutrition and physical activity. 5th ed. Copenhagen: Nordic Council of Ministers; 2014. Chapter 9, Physical activity; p. 203-207.

23. Henkin Y, Shai I, Zuk R, Brickner D, Zuilli I, Neumann L, et al. Dietary treatment of hypercholesterolemia: do dietitians do it better? A randomized, controlled trial. The American journal of medicine. 2000 Nov;109(7):549-55.

24. Svilaas A, Strom EC, Svilaas T, Borgejordet A, Thoresen M, Ose L. Reproducibility and validity of a short food questionnaire for the assessment of dietary habits. Nutrition, metabolism, and cardiovascular diseases : NMCD. 2002 Apr;12(2):60-70.

25. Liao KP, Solomon DH. Traditional cardiovascular risk factors, inflammation and cardiovascular risk in rheumatoid arthritis. Rheumatology (Oxford, England). 2013 Jan;52(1):45-52.

26. Rollefstad S, Kvien TK, Holme I, Eirheim AS, Pedersen TR, Semb AG. Treatment to lipid targets in patients with inflammatory joint diseases in a preventive cardio-rheuma clinic. Annals of the rheumatic diseases. 2013 Dec;72(12):1968-74.

27. World Medical Association Declaration of Helsinki: ethical principles for medical research involving human subjects. Jama. 2013 Nov 27;310(20):2191-4.

28. Johnson RK, Kennedy E. The 2000 Dietary Guidelines for Americans: What Are The Changes and Why Were They Made? Journal of the American Dietetic Association. 2000; 100(7):769-774.

29. Siri-Tarino PW, Sun Q, Hu FB, Krauss RM. Meta-analysis of prospective cohort studies evaluating the association of saturated fat with cardiovascular disease. Am J Clin Nutr. 2010 Mar;91(3):535-46.

30. Skeaff CM, Miller J. Dietary fat and coronary heart disease: summary of evidence from prospective cohort and randomised controlled trials. Annals of nutrition \& metabolism. 2009;55(1-3):173-201. 
31. Hannan EL. Randomized Clinical Trials and Observational Studies: Guidelines for Assessing Respective Strengths and Limitations. JACC: Cardiovascular Interventions. 2008; 1(3):211-217.

32. Guasch-Ferre M, Babio N, Martinez-Gonzalez MA, Corella D, Ros E, Martin-Pelaez S, et al. Dietary fat intake and risk of cardiovascular disease and all-cause mortality in a population at high risk of cardiovascular disease. Am J Clin Nutr. 2015 Dec;102(6):1563-73.

33. $\mathrm{Hu}$ FB, Manson JE, Willett WC. Types of dietary fat and risk of coronary heart disease: a critical review. Journal of the American College of Nutrition. 2001 Feb;20(1):5-19.

34. Brown L, Rosner B, Willett WW, Sacks FM. Cholesterollowering effects of dietary fiber: a meta-analysis. Am J Clin Nutr. 1999 Jan;69(1):30-42.

35. Ripsin CM, Keenan JM, Jacobs DR, Jr., et al. Oat products and lipid lowering. A meta-analysis. Jama. 1992 Jun 24;267(24):3317-25.

36. Khaw KT, Barrett-Connor E. Dietary fiber and reduced ischemic heart disease mortality rates in men and women: a 12-year prospective study. Am J Epidemiol. 1987 Dec;126(6):1093-102.

37. Wolk A, Manson JE, Stampfer MJ, Colditz GA, Hu FB, Speizer $\mathrm{FE}$, et al. Long-term intake of dietary fiber and decreased risk of coronary heart disease among women. Jama. 1999 Jun 2;281(21):1998-2004.

38. Helsedirektoratet [The Norwegian Directorate of Health]. Utviklingen i norsk kosthold 2015. [The development in the Norwegian diet]. Oslo: Helsedirektoratet; 2015. p. 8.

39. Avina-Zubieta JA, Choi HK, Sadatsafavi M, Etminan M, Esdaile JM, Lacaille D. Risk of cardiovascular mortality in patients with rheumatoid arthritis: a meta-analysis of observational studies. Arthritis and rheumatism. 2008 Dec 15;59(12):1690-7.

40. Cornelis MC, El-Sohemy A. Coffee, caffeine, and coronary heart disease. Current opinion in clinical nutrition and metabolic care. 2007 Nov;10(6):745-51.

41. Friedewald WT, Levy RI, Fredrickson DS. Estimation of the concentration of low-density lipoprotein cholesterol in plasma, without use of the preparative ultracentrifuge. Clinical chemistry. 1972 Jun;18(6):499-502.

42. Schumacher TL, Burrows TL, Rollo ME, Spratt NJ, Callister R, Collins CE. Effectiveness of a Brief Dietetic Intervention for Hyperlipidaemic Adults Using Individually-Tailored Dietary Feedback. Healthcare (Basel, Switzerland). 2016 Oct 11;4(4).

43. Jenkins DJ, Josse AR, Wong JM, Nguyen TH, Kendall CW. The portfolio diet for cardiovascular risk reduction. Current atherosclerosis reports. 2007 Dec;9(6):501-7.

44. Hjermann I, Velve Byre K, Holme I, Leren P. Effect of diet and smoking intervention on the incidence of coronary heart disease. Report from the Oslo Study Group of a randomised trial in healthy men. Lancet (London, England). 1981 Dec 12;2(8259):1303-10.

45. Ellingsen I, Hjerkinn EM, Arnesen H, Seljeflot I, Hjermann I, Tonstad S. Follow-up of diet and cardiovascular risk factors 20 years after cessation of intervention in the Oslo Diet and Antismoking Study. European journal of clinical nutrition. 2006 Mar;60(3):378-85.

46. LeFevre ML. Behavioral counseling to promote a healthful diet and physical activity for cardiovascular disease prevention in adults with cardiovascular risk factors: U.S. Preventive Services Task Force Recommendation Statement. Annals of internal medicine. 2014 Oct 21;161(8):587-93.
47. Krauss RM, Eckel RH, Howard B, Appel LJ, Daniels SR, Deckelbaum RJ, et al. AHA Dietary Guidelines: revision 2000: A statement for healthcare professionals from the Nutrition Committee of the American Heart Association. Circulation. 2000 Oct 31;102(18):2284-99.

48. Fulcher J, O'Connell R, Voysey M, Emberson J, Blackwell L, Mihaylova B, et al. Efficacy and safety of LDL-lowering therapy among men and women: meta-analysis of individual data from 174,000 participants in 27 randomised trials. Lancet (London, England). 2015 Apr 11;385(9976):1397-405.

49. Semb AG, Kvien TK, DeMicco DA, Fayyad R, Wun CC, LaRosa JC, et al. Effect of intensive lipid-lowering therapy on cardiovascular outcome in patients with and those without inflammatory joint disease. Arthritis and rheumatism. 2012 Sep;64(9):2836-46.

50. Li Y, Hruby A, Bernstein AM, Ley SH, Wang DD, Chiuve SE, et al. Saturated Fats Compared With Unsaturated Fats and Sources of Carbohydrates in Relation to Risk of Coronary Heart Disease: A Prospective Cohort Study. Journal of the American College of Cardiology. 2015 Oct 6;66(14):1538-48.

51. Catapano AL, Graham I, De Backer G, Wiklund O, Chapman MJ, Drexel H, et al. 2016 ESC/EAS Guidelines for the Management of Dyslipidaemias: The Task Force for the Management of Dyslipidaemias of the European Society of Cardiology (ESC) and European Atherosclerosis Society (EAS) Developed with the special contribution of the European Assocciation for Cardiovascular Prevention \& Rehabilitation (EACPR). Atherosclerosis. 2011 Jul;217(1):3-46.

52. Stanhope KL, Medici V, Bremer AA, Lee V, Lam HD, Nunez $\mathrm{MV}$, et al. A dose-response study of consuming high-fructose corn syrup-sweetened beverages on lipid/lipoprotein risk factors for cardiovascular disease in young adults. Am J Clin Nutr. 2015 Jun;101(6):1144-54

53. Rimm EB, Williams P, Fosher K, Criqui M, Stampfer MJ. Moderate alcohol intake and lower risk of coronary heart disease: meta-analysis of effects on lipids and haemostatic factors. BMJ (Clinical research ed). 1999 Dec 11;319(7224):1523-8.

54. Cook NR, Cutler JA, Obarzanek E, Buring JE, Rexrode KM, Kumanyika SK, et al. Long term effects of dietary sodium reduction on cardiovascular disease outcomes: observational follow-up of the trials of hypertension prevention (TOHP). BMJ (Clinical research ed). 2007 Apr 28;334(7599):885-8.

55. He FJ, Li J, Macgregor GA. Effect of longer-term modest salt reduction on blood pressure. Cochrane Database Syst Rev. 2013 Apr 30(4):Cd004937.

56. Kelly J, Khalesi S, Dickinson K, Hines S, Coombes JS, Todd AS. The effect of dietary sodium modification on blood pressure in adults with systolic blood pressure less than $140 \mathrm{mmHg}$ : a systematic review. JBI database of systematic reviews and implementation reports. 2016 Jun;14(6):196-237.

57. World Health Organization (WHO). Diet, nutrition and the prevention of chronic diseases: Report of the joint WHO/FAO expert consultation. Geneva: WHO; 2003. (WHO Technical Report Series; 916).

58. Kostråd for å fremme folkehelsen og forebygge kroniske sykdommer Metodologi og vitenskapelig kunnskapsgrunnlag Nasjonalt råd for ernæring 2011. [Dietary advice to promote public health and Prevent chronic diseases Methodology and fundation of scientific knowledge National Nutrition Council 2011]. Oslo: Helsedirektoratet [The Norwegian Directorate of Health]; 2011. Chapter 4, Prinsipper og metodologi som ligger til grunn for de norske kostrådene [Principles and methodology 
underpinning the Norwegian dietary guidelines]; p. 29-49. Norwegian.

59. Conlin PR, Chow D, Miller ER, 3rd, et al. The effect of dietary patterns on blood pressure control in hypertensive patients: results from the Dietary Approaches to Stop Hypertension (DASH) trial. American journal of hypertension. 2000 Sep;13(9):949-55.

60. Collart F, de Timary P, Dom G, Dor BD, Duprez D, Lengele JP, et al. Alcohol-induced hypertension: an important healthcare target in Belgium. Acta clinica Belgica. 2015 Dec;70(6):389-95.

61. Due A, Toubro S, Stender S, Skov AR, Astrup A. The effect of diets high in protein or carbohydrate on inflammatory markers in overweight subjects. Diabetes, obesity \& metabolism. 2005 May;7(3):223-9.

62. Pedersen JI, Anderssen S, Hjartåker A. Kostdata, innsamling, bearbeiding og kvalitet. [Dietary data, collection, processing and quality]. In: Pedersen JI, Anderssen S, Hjartåker A, editors. Grunnleggende ernæringslære. [Basic knowledge of nutrition]. 2. ed. Oslo: Gyldendal akademisk; 2012. p. 22-43. Norwegian.

63. Molven I, Retterstol K, Andersen LF, Veierod MB, Narverud I, Ose L, et al. Children and young adults with familial hypercholesterolaemia $(\mathrm{FH})$ have healthier food choices particularly with respect to dietary fat sources compared with non-FH children. Journal of nutritional science. 2013;2:e32.
64. Hansen-Krone IJ, Enga KF, Njolstad I, Hansen JB, Braekkan SK. Heart healthy diet and risk of myocardial infarction and venous thromboembolism. The Tromso Study. Thrombosis and haemostasis. 2012 Sep;108(3):554-60.

65. Wiens L, Schulzer M, Chen C, Parinas K. Reliability and validity of the SmartDiet Canadian version questionnaire. Journal of the American Dietetic Association. 2010 Jan;110(1):101-5.

66. Lin JS, O'Connor EA, Evans CV, Senger CA, Rowland MG, Groom HC. U.S. Preventive Services Task Force Evidence Syntheses, formerly Systematic Evidence Reviews. Behavioral Counseling to Promote a Healthy Lifestyle for Cardiovascular Disease Prevention in Persons With Cardiovascular Risk Factors: An Updated Systematic Evidence Review for the U.S. Preventive Services Task Force. Rockville (MD): Agency for Healthcare Research and Quality (US); 2014.

\section{* Maria Grorud Fagerhøi, MS, RD}

Department of Clinical Service,

Diakonhjemmet Hospital

P.O. Box 23 Vinderen

NO-0319 Oslo, Norway

Tel: +4797| 68724

Email: MariaGrorud.Fagerhoi@diakonsyk.no 